\section{Comparison of Gastric pH in Emergency versus Elective Caesarean Sections}

\section{Abstract}

Background: The volume of the gastric fluids and the gastric $\mathrm{pH}$ both are affected during pregnancy and surgery. The gastric fluid volume and $\mathrm{pH}$ are also affected by the mode of surgery (elective caesarean section and emergency caesarean).

Objective: The predetermined aim of this study was to compare the gastric fluid $\mathrm{pH}$ in emergency with elective caesarean sections.

Method: The study was conducted in Divisional Headquarters Teaching Hospital, Mirpur, Azad Kashmir and the sample population was consisted of 150 patients. The sample was divided into two groups, the patients with emergency caesarean section and elective caesarean section group. The gastric volume and gastric $\mathrm{pH}$ were detected in both groups of the study.

Results: The group of the patients in the emergency caesarean section showed lower gastric $\mathrm{pH}$ value $(2.16 \pm 0.64)$ and the gastric acid volume was (26.33 \pm 10.59). In comparison, the gastric $\mathrm{pH}$ value for elective caesarean section was $(4.56 \pm 1.28)$ and gastric acid volume was $(11.65 \pm 4.37)$ respectively. The results were found to be significant at $p$-value $<0.05$.

Conclusion: The results of the study concluded that gastric volume was significantly higher and gastric $\mathrm{pH}$ was significantly lower in emergency caesarean section as compared to elective caesarean section.

Keywords: Gastric fluid volume; Gastric pH; Elective caesarean section; Emergency caesarean section

Received: February 26, 2018; Accepted: April 20, 2018; Published: April 30, 2018

\section{Shahid Adalat Chaudhry ${ }^{1 *}$, Sadia Fahim ${ }^{2}$ and Aurooj Fatima²}

1 Department of Anesthesiology, Hashmat Medical \& Dental College, Jalapur Jattan, Gujrat, Pakistan

2 Department of Gynaecology \& Obstetrics, Mohtarma Benazir Bhutto Shaheed Medical College, Mirpur, Azad Kashmir, Pakistan

Corresponding author:

Dr. Shahid Adalat Chaudhry

\section{Đ drshahidadalat@yahoo.com}

Assistant Professor, Department of Anesthesiology, Hashmat Medical \& Dental College, Jalapur Jattan, Gujrat, Pakistan.

Tel: +92-344-5163749

Citation: Chaudhry SA, Fahim S, Fatima A (2018) Comparison of Gastric pH in Emergency versus Elective Caesarean Sections. Int J Anesth Pain Med. Vol.4 No.1:5

\section{Introduction}

Pregnancy is the condition that represents physiological adaptations, few adaptations become evident during first trimester of delivery while few of them remain persistent after the delivery. Pregnancy is the state that affects the functions of almost all body systems including gastrointestinal (GI) tract. The changes in physiology of $\mathrm{Gl}$ tract includes the decrease in $\mathrm{pH}$ of the gastric fluids, gastric emptying and volume of the gastric fluids $[1,2]$. This whole condition is referred as gastro-esophageal reflux disease or GERD [3]. The exacerbation of the gastric symptoms occurs due to anxiety, labor pains, and opioids etc. [4-7].

Both the central and peripheral overlapping of the neural, paracrine and hormonal pathway controls the secretion of gastric acid from the parietal cells. The increased release of gastric acid may cause gastroduodenal injury while less production interfere the absorption of calcium, iron, vitamin $B_{12}$ several drugs and may also pre-dispose the patients to enteric infections. There are many factors that are associated with the variation of acid secretion due to food intake. Therefore, it is essential to have an understanding of these factors in order to have the precise knowledge pathophysiology [8].

The effects of these factors may lead to increased risks of aspiration and vomiting which may lead to pneumonitis. The word aspiration is the mis-direction of the oropharyngeal and gastric contents into larynx and lower respiratory tract. The nature, frequency and quantity of aspirated material may results in variety of pulmonary syndromes. The syndrome includes the Mendelson's syndrome or aspiration pneumonia which occurs due to the aspiration of the gastric contents and aspiration pneumonia which is bacterial infection and caused by the aspiration of oropharyngeal secretions. This is the reason that any 
conditions causing the increased gastric acid volume, decreased gastric $\mathrm{pH}$ or the disruption in the defense mechanisms may lead to any of these syndromes [9].

The term caesarean section is used to represent delivery of the baby by uterine or abdominal incision. The caesarean section is used for the maternal and fetal health, and safe delivery. The caesarean section may also be termed as emergency section or elective section. This is carried out after the age of viability which is 24 weeks. In the case of caesarean section, general or spinal anesthesia is more suitable [10].

Anesthesia is related to many factors and these factors may affect the Gl physiology. During immediate pre-operative period, the food intake can affect the gastric emptying and also produces pronounced effect to enhance gastro-esophageal reflux [11]. Furthermore, at the time of induction of anesthesia, the cricoid pressure may decrease the lower esophageal sphincter tone [12]. These factors may act as the factors that may cause a high risk to the pregnant woman to develop regurgitation and aspiration which may present as pneumonitis. The $\mathrm{pH}$ and the volume of aspirated gastric content affect the severity of pneumonitis. The magnitude of the $\mathrm{pH}$ in case of emergency caesarean section is $4.9 \pm 1.1$ and for elective caesarean section, the mean value is $3.11 \pm 1.17$ [13].

The gastric volume of $25 \mathrm{ml}$ or more and gastric $\mathrm{pH}$ of 2.5 or less is associated with the increased risk of developing pneumonitis in the parturient. Thus, it is recommended for all parturient, especially those with emergency caesarean section to have prophylaxis against pulmonary aspiration and regurgitation [14]. A figure expressing the acidity or alkalinity of a solution on a logarithmic scale on which 7 is neutral, lower values are more acid and higher values more alkaline. The $\mathrm{pH}$ is equal to $-\log _{10} \mathrm{c}$, where $\mathrm{c}$ is the hydrogen ion concentration in moles per liter.

Emergency caesarean section is carried out in the cases when there is an immediate threat to the life of fetus or woman, and if the health of fetus or mother is compromised. The emergency CS is also carried out in cases when there is a need of early delivery. The elective caesarean section is carried out before the onset of labor for specific clinical indications.

The rationale for choosing this topic is that the literature review of evidence based studies has revealed that there is no study that has compared the $\mathrm{pH}$ and volume of gastric contents between pregnancy and elective caesarean section. Therefore, this study was conducted to understand the association between caesarean section and gastric $\mathrm{pH}$ and volume of gastric contents. The other rationale of this study was to appreciate the importance of aspiration prophylaxis group.

\section{Objective}

The predetermined aim of this study was to compare the gastric fluid $\mathrm{pH}$ in emergency versus the elective caesarean sections.

\section{Materials and Methods}

This theory was based on hypothesis that the $\mathrm{pH}$ of gastric fluid in elective caesarean is higher than the $\mathrm{pH}$ of emergency caesarean section. This study was based on the cross-sectional methodology and the setting for this study was operation theatre of Divisional Headquarters Teaching Hospital, Mirpur, Azad Kashmir. The sample size was consisted of 150 cases that were divided into two equal groups. The first group consisted of 75 cases which were elective while second group consisted of 75 cases of emergency caesarean section. Confidence level of the study was $95 \%$ while the control of study was estimated as $80 \%$. The magnitude i.e. mean \pm SD of the $\mathrm{pH}$ in emergency caesarean was taken $4.9 \pm 1.1$ while for the elective caesarean section, it was $3.11 \pm 1.17$. Non-probability purposive sampling technique was used in the study.

\section{Inclusion and exclusion criteria}

There were some inclusion and exclusion criteria that were used for the selection of sample. The inclusion criteria for the study was the patients that belong to the age group $20-40$ years and all of the patients were ASA II. The patients that were going through the normal gestational period were included in the study and all caesarian cases were those that were conducted by using general anesthesia. Duration of the surgery was from 30-90 minutes and for the sample collection, patients were kept in the supine position during anesthesia.

Exclusion criteria for the study was the patients that had some pathology, for instance, achalasia of esophagus, diaphragmatic hernia, peptic ulcer, etc. The patients with difficulty of the anticipated intubation, morbid obesity and gastro-esophageal reflux and Zolliger-Ellison syndrome were excluded from the study.

\section{Data Collection}

Patients that met the inclusion criteria of the study were subdivided into emergency and elective patients. The caesarean groups were labelled as emergency and elective and each group consisted of 75 patients. The mandatory monitoring for the measurement of pulse, blood pressure, capnography etc. were carried out. Pulse oximetry, capnography, ECG and noninvasive blood pressure techniques were used for mandatory monitoring. After the step of pre-oxygenation, the application of general anesthesia was carried out by rapid sequence indication with $5 \mathrm{mg} / \mathrm{kg}$ thiopentone sodium which is followed by 1.5 $\mathrm{mg} / \mathrm{kg}$ of succinylcholine sodium. After the induction of long acting relaxant, orogastric tube no. 16 was passed to take the gastric aspirate. If there was any difficulty in the aspiration, the manipulation in the orogastric tube was carried out for obtaining the aspirate successfully. The $\mathrm{pH}$ was measured by using a calibrated $\mathrm{pH}$ meter while for the calculation of aspirate volume, $20 \mathrm{ml}$ syringe was used. The $2 \mathrm{mg} / \mathrm{kg}$ of tramadol was used as the analgesic agent and was maintained with inhalation agent in $100 \% \mathrm{O}_{2}$.

\section{Data Analysis}

The data analysis was carried out by using the "Statistical Package for Social Sciences (SPSS) version 20. Data cleaning 
was carried out after its entry for the removal of illogical and missing entries. The study groups, as described earlier, were the emergency versus elective caesarean section and gastric $\mathrm{pH}$ was the outcome variable. The comparison of the $\mathrm{pH}$ value of both groups was carried out by using the t-test. The percentages, frequencies, mean and the standard variables for the $\mathrm{pH}$ and age were calculated by using the descriptive statistics.

\section{Ethical Consideration}

Before conducting the study, the ethical approval was taken from the ethical committee of the hospital. Furthermore, a written consent was also taken from the patients who were fulfilling the inclusion criteria of the study.

\section{Results}

\section{Patients' distribution according to age}

The mean age of the patients in the emergency caesarean section group was between the 20-30 years (mean \pm SD was $28.17 \pm 4.21$ years). Among all the patients of this group, $28 \%$ of the patients i.e. 21 patients had the age range between 20-25 years, $50.7 \%$ or 38 patients had the age range between $26-30$ years. In addition, $14.6 \%$ patients (11 patients) were those who had the age between $31-35$ years and $6.7 \%$ (5 patients) had age range between $36-40$ years. The distribution of the patients by age is shown in Table 1.

In the elective caesarean section group, the mean age of the patient was found to be $27.82 \pm 4.48$ years and the age was ranging from $20-40$ years. $38.6 \%$ (29 patients) of the patient were of the age group $20-25$ years and $36 \%$ patients ( 27 patients) had the age range of $26-30$ years. Furthermore, $18.7 \%$ patients (14 patients) were $31-35$ years old and $6.7 \%$ of the patients ( 5 patients) were having the age between $36-40$ years. The result for the age distribution of elective and emergency caesarean is also shown in Table 1.

\section{Patients' distribution according to weight}

The patients of the emergency caesarean group had the mean weight range of $65-98 \mathrm{~kg}$ (mean age=83.5 $\pm 5.99 \mathrm{~kg}$ ). Among all the patients, $6.7 \%$ patients ( 5 patients) had the weight range of $65-75 \mathrm{~kg}, 52 \%$ of the patients (39 patients) had the weight range $76-85 \mathrm{~kg}$. Moreover, $40 \%$ patients (30 patients) had weight range $86-95 \mathrm{~kg}$ and $1.3 \%$ i.e. 1 patient had weight greater than $95 \mathrm{~kg}$.

The patients of the elective caesarean group had the mean

Table 1 Distribution of patients by age $(n=150)$.

\begin{tabular}{|c|c|c|c|c|}
\hline \multirow{2}{*}{ Age in Years } & \multicolumn{2}{|c|}{ Elective } & \multicolumn{2}{c|}{ Emergency } \\
\cline { 2 - 5 } & $\begin{array}{c}\text { No. of } \\
\text { Patients }\end{array}$ & Percentage & $\begin{array}{c}\text { No. of } \\
\text { Patients }\end{array}$ & Percentage \\
\hline $20-25$ & 29 & 38.6 & 21 & 28 \\
\hline $26-30$ & 27 & 36 & 38 & 50.7 \\
\hline $31-35$ & 14 & 18.7 & 11 & 14.6 \\
\hline $36-40$ & 5 & 6.7 & 5 & 6.7 \\
\hline Mean \pm SD & $27.82 \pm 4.48$ & $28.17 \pm 4.21$ \\
\hline Range & \multicolumn{2}{|c|}{$20-40$} & \multicolumn{2}{|c|}{$21-38$} \\
\hline
\end{tabular}

Table 2 Distribution of patients by weight $(n=150)$.

\begin{tabular}{|c|c|c|c|c|}
\hline \multirow{2}{*}{ Weight in Kg } & \multicolumn{2}{|c|}{ Elective } & \multicolumn{2}{|c|}{ Emergency } \\
\hline & $\begin{array}{l}\text { No. of } \\
\text { Patients }\end{array}$ & Percentage & $\begin{array}{l}\text { No. of } \\
\text { Patients }\end{array}$ & Percentage \\
\hline $65-75$ & 8 & 10.7 & 5 & 6.7 \\
\hline $76-85$ & 46 & 61.3 & 39 & 52 \\
\hline $86-95$ & 21 & 28 & 30 & 40 \\
\hline$>95$ & 0 & 0 & 1 & 1.3 \\
\hline Mean \pm SD & \multicolumn{2}{|c|}{$81.9 \pm 5.49$} & \multicolumn{2}{|c|}{$83.5 \pm 5.99$} \\
\hline Range & \multicolumn{2}{|c|}{$65-90$} & \multicolumn{2}{|c|}{$65-98$} \\
\hline
\end{tabular}

Table 3 Distribution of patients by $\mathrm{pH}$ value and gastric volume aspirated $(n=150)$.

\begin{tabular}{|c|c|c|c|c|}
\hline & $\begin{array}{r}\text { Emergency } \\
\text { Cesarean } \\
\text { Section }\end{array}$ & $\begin{array}{r}\text { Elective } \\
\text { Cesarean } \\
\text { Section }\end{array}$ & p-value & Significance \\
\hline $\begin{array}{r}\text { Mean of } \mathrm{pH} \\
\text { value }\end{array}$ & $2.16 \pm 0.64$ & $4.56 \pm 1.28$ & $0.000(<0.05)$ & Significant \\
\hline $\begin{array}{r}\text { Mean of gastric } \\
\text { volume }\end{array}$ & $26.33 \pm 10.59$ & $\begin{array}{r}11.65 \pm \\
4.37\end{array}$ & $0.000(<0.05)$ & ) Significant \\
\hline
\end{tabular}

weight range of $65-90 \mathrm{~kg}$ (mean age=81.9 $\pm 5.49 \mathrm{~kg}$ ). There were $8(10.7 \%)$ patients were of the weight range between 65 to 75 $\mathrm{kg}$ and $61.3 \%$ of patients (46 patients) had the weight range between 76 to $85 \mathrm{~kg}$. Additionally, 28\% patients (21 patients) had the weight between the ranges of 85 to $95 \mathrm{~kg}$. There was no patient with the weight $>95 \mathrm{~kg}$. The result for distribution of patients with respect to weight is also shown in Table 2.

\section{Distribution of the patients by the comparison of ph value and volume of the gastric aspirate}

The $\mathrm{pH}$ and volume of the gastric aspirate were also compared between both groups. The mean value for the $\mathrm{pH}$ for the patients of the emergency caesarean section was $2.16 \pm 0.64$ and the mean for the elective caesarean group was $4.56 \pm 1.28$. The results were found to be significant at $\mathrm{p}$-value $<0.05$ when the $\mathrm{pH}$ of both groups was compared.

The aspirated gastric acid volume of the patients was also compared. In the emergency caesarean section group, the mean gastric acid volume aspirated was $26.33 \pm 10.59 \mathrm{ml}$, while the mean value for elective group was $11.65 \pm 4.37 \mathrm{ml}$. The results of both groups were compared and it was found that emergency caesarean section volume was more than that of elective group and found to be statistically significant at $p$-value $<0.05$. The results for comparison of $\mathrm{pH}$ and volume of gastric aspirate are shown in Table 3.

\section{Discussion}

It is evident from the literature [15-17] that the issue regarding aspiration problems and gastric acidity has been under debate for several years. The role of the gastric $\mathrm{pH}$ and its management has been studied by various researchers and several studies are being conducted in this regard. The present study is among the few studies that are being conducted globally to compare the gastric $\mathrm{pH}$ of patients from elective and emergency caesarean section 
group. The review of literature has revealed that only fewer studies are conducted on this important matter of consideration.

In a study conducted by Ngwingtin et al. [18] the researchers studied 97 patients for the evaluation of changes in the volume of the gastric content and gastric $\mathrm{pH}$ during the state of pregnancy and labor. There were several study parameters that were used for this study and one of the basic study parameters was the measurement of gastric $\mathrm{pH}$ and volume of the gastric content after the induction of the anesthesia. The same parameters were also used for this study, however in the reference study, the patients were divided into 3 groups and these three groups were; group 1 consisted of 39 patients that received the treatment for elective caesarean section, group 2 included 44 patients with some elective gynecological surgery and the group 3 consisted of 14 patients who had emergency caesarean section.

The aim of the study conducted by Ngwingtin et al. [18] was to determine that whether there is any modification in the mean $\mathrm{pH}$ or volume of the gastric content due to pregnancy or labor. The mean values for the three groups of the study revealed that no significant differences occur between these groups. The results of this study concluded that there is no effect of the pregnancy or labor on the gastric $\mathrm{pH}$. If the results of the gastric volume are considered, a significant difference was found between the group 1 and 3 at $p<0.01$ and similarly significant differences were observed for group 2 and 3 . This study resembles current study in terms of study parameters and methods i.e. measurement of gastric volume and gastric $\mathrm{pH}$. However, the results of the present study differ from the study conducted by Ngwingtin et al. [18]. This can be revealed from the fact that in the study conducted by Ngwingtin et al. [18] the gastric $\mathrm{pH}$ in emergency caesarean section was 2.57 while in the present study the $\mathrm{pH}$ was $2.16 \pm$ 0.64 . The value of the gastric $\mathrm{pH}$ for the elective caesarean was $2.77 \pm 0.42$, while in the present study; the mean gastric $\mathrm{pH}$ was $4.56 \pm 1.28$ which is a huge difference from the other values. The results of both studies illustrated that gastric $\mathrm{pH}$ for the elective caesarean section is comparatively high. The results of the past study were of no clinical significance, however, the results of this study were found to be clinically significant.

A clinical trial was conducted by Hong et al. in which researchers found the difference of gastric $\mathrm{pH}$ and volume between two groups, i.e. the pregnant group and non-pregnant group. The observation of the clinical trial showed that gastric $\mathrm{pH}$ of the pregnant women was lower than the gastric $\mathrm{pH}$ level of the nonpregnant women $(2.4 \pm 1.4$ for the pregnant women and $3.0 \pm$ 1.9 for the non-pregnant women at $p<0.05)$. On the other hand, the gastric volume was found to be high for the pregnant women as compared to non-pregnant group (the value for the pregnant women was $0.49 \pm 0.4 \mathrm{~mL} / \mathrm{kg}$ vs. $0.24 \mathrm{~mL} / \mathrm{kg}$ for non-pregnant women at $\mathrm{p}<0.05)$. However, there was no significant difference in the serum gastrin level of the both groups (32.1 \pm 12.3 vs. 28.2 $\pm 8.3 \mathrm{pg} / \mathrm{mL}$ ) [19].

Naguchi et al. [18] carried out a clinical trial for investigation of the impact of anesthesia on the gastric secretion. They used different anesthetic techniques for the measurement of gastric volume and $\mathrm{pH}$ during anesthesia. In the anesthetic techniques, the halothane anesthesia was induced in three groups, enflurane anesthesia, halothane plus thoracic epidural block, halothane without premedication of atropine. The $\mathrm{pH}$ was increased for all age groups and more profoundly in the old age patients after the induction of halothane anesthesia. The enflurane anesthesia and halothane anesthesia with thoracic epidural block also increased the gastric $\mathrm{pH}$. The anesthesia group without pre-medication of atropine, showed no significant effect on the gastric $\mathrm{pH}$ or the gastric acid volume. The results of this study concluded that during the halothane anesthesia, parasympathetic blockage is the basic reason for increase in the gastric $\mathrm{pH}$ [20].

In the present study, the volume of gastric aspiration and gastric $\mathrm{pH}$ were used as the outcome variables. These parameters are extensively used in several clinical trials. Stuart et al. [21] conducted a clinical trial for the comparison of different prophylactic drugs in order to find the effectiveness of these drugs in gastric $\mathrm{pH}$. The sample size of the study was 384 patients and who required the emergency caesarean section with the aid of general anesthesia. The general anesthesia was received at random one of six acid prophylaxis procedures till the decision for surgery was finalized. The parameter for this study was $\mathrm{pH}$ level 4. The outcomes of the study have concluded that measurement of gastric $\mathrm{pH}$ is the universal parameter which can be used for the determination of the $\mathrm{Gl}$ or aspiration related problems in the obstetric patients [21].

The gastric volume and $\mathrm{pH}$ can be used as a parameter for the measurement of risks of aspiration. The higher risks for the aspiration are the gastric $\mathrm{pH}<2.5$ and gastric fluid volume $>0.4$ $\mathrm{ml} / \mathrm{kg}$. These are the widely accepted indicators for different clinical trials and the measurement of these parameters can be effective for the prevention of risks of aspiration [22].

There is an essential requirement to develop the guidelines and policies in the setups to reach the optimal results and parameters. These policies include the addition of some gastric $\mathrm{pH}$ neutralizing agents, for instance, $\mathrm{H}_{2}$ receptor blockers, antacids, or conducting aspiration of the gastric contents before emergency caesarean section.

\section{Limitations and Recommendations}

There are some limitations of the study. The sample size of the study was small and the study was not a double blinded study. There are few recommendations regarding this study. Further evidence based studies or clinical trials should be conducted on a large sample size.

\section{Conclusion}

The results of this study concluded that the patient undergoing emergency caesarean section had lower gastric $\mathrm{pH}$ as compared to the patients that had undergone the elective caesarean section. The difference between the two groups was found to be statistically significant. There is a pre-requisite requirement to conduct large multicenter clinical trials with larger sample size so that the facts concluded from this study can be proved. 


\section{References}

1 Howell SM, Serafini M (2010) Physiology and Anesthesia for Obstetrics. Anesthesia Student Survival Guide 3: 303-323.

2 Hill CC, Pickinpaugh J (2009) Physiologic changes in pregnancy. Surg Clin North Am 88: 391-401.

3 Morgan GE, Mikhail MS, Murray MJ (2006) Maternal and fetal physiology and anesthesia. Clinical anesthesiology. New York: McGraw-Hill pp: 874-889.

4 Malfertheiner SF, Malfertheiner MV, Mönkemüller K, Röhl FW, Malfertheiner P, et al. (2009) Gastroesophageal reflux disease and management in advanced pregnancy: a prospective survey. Digestion 79:115-120.

5 Gyte GM, Richens Y (2006) Routine prophylactic drugs in normal labor for reducing gastric aspiration and its effects. Cochrane Database Syst Rev 2006: 3.

6 Gonenne J, Camilleri M, Ferber I, Burton D (2005) Effect of alvimopan and codeine on gastrointestinal transit: a randomized controlled study. Clin Gastroenterol Hepatol 3: 784-791.

7 Geeraerts B, Vandenberghe J, Van Oudenhove L, Gregory L, Aziz Q, et al. (2005) Influence of experimentally induced anxiety on gastric sensorimotor function in humans. Gastroenterol 129: 1437-1444.

8 Schubert ML (2006) Gastric secretion. Current Opinion in Gastroenterology 20:519-525.

9 Marik PE (2001) Aspiration pneumonitis and aspiration pneumonia. New England J Med 344: 665-671.

10 Hassan S, Javaid KM, Tariq S (2008) Emergency caesarean section; Comparative analysis of problems encountered between patients of elective caesarean section and patient for whom elective caesarean section was planned but ended up in emergency. Professional Med J 15: 211-215.

11 Wildi SM, Tutuian R, Castell DO (2004) The influence of rapid food intake on postprandial reflux: studies in healthy volunteers. Am. J. Gastroenterol 99: 1645-1651.

12 Garrard A, Campbell AE, Turley A, Hall JE (2004) The effect of mechanically-induced cricoid force on lower esophageal sphincter pressure in anaesthetized patients. Anesthesia 59: 435-439.

13 Taqi A (1994) Measurement of volume and $\mathrm{pH}$ of gastric contents using blind gastric aspiration (dissertation): Karachi College of Physicians and Surgeons Pakistan.

14 Morgan GE, Mikhail MS, Murray MJ, Kleinman W, Nitti GJ, et al. (2002) Clinical anesthesiology New York: McGraw-hill.

15 Joachim L, Mac N, Tore L, Andrews L, David J, et al. (2006) Prospective follow up data from the ProGERD study suggest that GERD is not a categorical disease. Am J Gastroenterol 101: 2457-2462.

16 Vaezi MF (2005) Atypical manifestations of gastroesophageal reflux disease. MedGenMed 7: 25-26.

17 Irwin RS (2006) Chronic cough due to gastroesophageal reflux disease: ACCP evidence-based clinical practice guidelines. Chest 129: 80S-94S.

18 Ngwingtin I, Hardy F, Hamer R, Glomaud D (1987) Changes in the $\mathrm{pH}$ and volume of gastric contents during pregnancy and labor. Cah Anesthesiol 35:607-609.

19 Hong JY, Park W, Oh JI (2005) Comparison of gastric contents and serum gastrin concentration in pregnant and non pregnant women. J Clin Anesthesia 17: 415-455.

20 Noguchi J (1989) Effects of anesthesia, premedication and age on gastric $\mathrm{pH}$ and volume. Masui 38: 852-858.

21 Stuart JC, Kan AF, Rowbottom SJ, Yau G, Gin T (1996) Acid aspiration prophylaxis for emergency Caesarean section. Anesthesia 51: 415-421.

22 Negalhaut JJ (2003) Aspiration prophylaxis: Is this the time for change in our practice. AANA J 71: 299-302. 